Research Article

Wei Ba*, Ziyuan Wang, Xuesong Li, and Chunwei Gu

\title{
Three-dimensional optimal design of a cooled turbine considering the coolant-requirement change
}

https://doi.org/10.1515/phys-2019-0080

Received Sep 03, 2019; accepted Oct 29, 2019

Abstract: Cooling technology is widely applied in modern turbines to protect the turbine blades, and extracting high-pressure cooling air from a compressor exerts a remarkable influence on the gas-turbine performance. However, the three-dimensional optimal design of a turbine in modern industrial practice is usually carried out by pursuing high component efficiency without considering possible changes in coolant requirement; hence, it may not exactly lead to improvement in the gas-turbine cycle efficiency. In this study, the turbine stator was twisted and leaned to achieve higher comprehensive efficiency, which is the cycle-based efficiency definition for a cooled turbine that considers both turbine aerodynamic performance and coolant requirement. First, the influence of twist and compound lean on turbine aerodynamic performance, considering stator-hub leakage, was investigated. Then, a method to predict the coolant requirement for turbines with different stator designs was applied, to evaluate coolant-requirement change at the design condition. The optimized turbines were finally compared to demonstrate the necessity of considering the coolant-requirement change in the optimal design. This indicated that proper twisting to open the throat area in the stator hub and compound lean to the pressure surface side could help improve the cooled-turbine comprehensive efficiency.

Keywords: Cooled turbine; Comprehensive efficiency; Coolant requirement; Blade twist; Compound lean

PACS: 47.60.Dx, 88.05.Bc

^Corresponding Author: Wei Ba: Tsinghua University Beijing, China; Email: bw15@mails.tsinghua.edu.cn

Ziyuan Wang, Xuesong Li, Chunwei Gu: Tsinghua University Beijing, China

ə Open Access. ๑ 2019 W. Ba et al., published by De Gruyter. (cc) BY License

\section{Nomenclature}

$\boldsymbol{d q}$ heat transfer flow rate, $\mathrm{J} / \mathrm{s}$

$\boldsymbol{f}_{c}$ coolant fraction

h specific enthalpy, $\mathrm{J} / \mathrm{kg}$, or convective heat-transfer coefficient, $\mathrm{W} /\left(\mathrm{m}^{2} \cdot \mathrm{K}\right)$

$\Delta \boldsymbol{l}$ thickness of blade wall, $\mathrm{m}$

$\boldsymbol{m}$ mass flow rate, $\mathrm{kg} / \mathrm{s}$

$\mathbf{N u}$ Nusselt number

$\boldsymbol{R e}$ Reynolds number

$\boldsymbol{T}$ temperature, $\mathrm{K}$

$\boldsymbol{W}$ specific work, $\mathrm{J} / \mathrm{kg}$

\section{Greek symbols}

\author{
$\gamma$ specific-heat ratio \\ $\eta$ efficiency \\ $\eta_{c}$ cooling efficiency \\ $\lambda$ heat-conductivity coefficient, $\mathrm{W} /(\mathrm{m} \cdot \mathrm{K})$ \\ $\pi_{T}$ turbine-expansion ratio
}

\section{Subscripts}

1 compressor inlet

3 turbine inlet

4 turbine outlet

$\boldsymbol{a c}$ actual process

c coolant

Com comprehensive efficiency

g mainstream gas

id ideal process

$\boldsymbol{m}$ blade metal

$\boldsymbol{t}$ total condition

$\boldsymbol{T}$ turbine 


\section{Introduction}

Turbine inlet temperatures have been increased to improve the performance of modern gas turbines, and cooling technologies are therefore widely applied [1]. However, extracting high-pressure cooling air from the compressors also deteriorates the gas-turbine cycle efficiency, and decreasing the coolant fraction while keeping the hot component under a critical temperature is important. In the traditional three-dimensional (3D) blade redesign procedure, the turbines are always optimized for a given mass flow rate and expansion ratio to achieve higher aerodynamic efficiency, without considering the possible coolant-requirement change caused by the aerodynamic redesign [2]. Therefore, the traditional redesign method can lead to a turbine design with higher component efficiency but may not maximize the gas-turbine cycle efficiency, which is also highly influenced by the coolant fraction. Therefore, additional work is still needed to develop a turbine redesign method further, which considers both the turbine aerodynamic performance and change in the coolant requirement.

Blade twist, lean, and sweep have been implemented to control the flow in modern turbine designs, and a detailed review was presented by Denton and Xu [3]. In industrial applications, blade lean has been applied to increase the stage reaction [4], control endwall losses [5], and reduce tip-leakage loss [6]. Blade twist near the endwalls has been investigated to control the local pressure distribution and outlet angle, and it is interesting to find that both closing [7] and opening [8] of the blade throat near the endwalls have been proven to positively affect the turbine efficiency. Although a conflict exists between the blade-twist effects on the turbine performance, opening the throat near the endwall has been proven to reduce both loading and pressure drop across the blade near the endwall.

However, the influence of 3D blade redesign on statorhub leakage has been neglected in previous research $[9$, 10], and the study by Rosic and $\mathrm{Xu}$ [11] demonstrated that the stator-hub leakage exerted an obvious influence on the turbine performance when the stator was leaned. Therefore, the stator-hub leakage is considered in the current research to predict the influence of blade 3D design more accurately. The aforementioned research studies demonstrated that blade 3D redesign can be a promising method to improve turbine aerodynamic efficiency further [12]. However, the possible coolant-requirement change caused by the blade redesign has been neglected.
In modern cooled turbines, a significant interaction effect between the main flow and coolant is present [13], and a large coolant fraction exerts a significant negative influence on the gas-turbine cycle performance [14]. Therefore, both aerodynamic efficiency and coolant-requirement fraction are important criteria for evaluating the cooledturbine comprehensive performance, which influence the gas-turbine cycle performance, and should be carefully considered during the turbine design. The cycle-based comprehensive efficiency of a cooled turbine [15] was developed as a method for evaluating the optimization design of cooled turbines, which considered the influence of changes in turbine aerodynamic performance and coolant fraction on the cycle efficiency. Therefore, maximum cooled-turbine comprehensive efficiency was considered as the optimized objective in the current research to improve the cycle performance $[16,17]$, and the optimized designs were compared to demonstrate the importance of considering coolant-requirement change during turbine design.

In this research, a two-stage high-pressure turbine was redesigned to evaluate the influence of blade twist and compound lean on the turbine comprehensive performance in an environment with a stator-hub leakage and a coolant-requirement change. The GE E3 high-pressure turbine [18] was selected as the baseline design. The second stator was modified with different levels of twist and compound lean, whereas the blade was twisted in different directions at the hub and tip to keep the turbine mass flow rate constant. Turbines with different stator designs were simulated using ANSYS CFX [19] and then compared to investigate the influence of the blade redesign on the turbine aerodynamic performance and stator-hub leakage. The turbine coolant-requirement change was evaluated using a coolant-prediction model that considered the bladebending force change, which directly influenced the blademetal temperature tolerance.

To analyze the combined effects of the changes in the turbine aerodynamic efficiency and coolant requirement on the gas-turbine cycle performance, the optimized turbine with the highest comprehensive efficiency and that with the highest aerodynamic efficiency were compared to demonstrate the necessity of considering the coolantrequirement change in the turbine redesign.

\section{Methodology}

Turbine optimal design method is provided in this chapter, included blade modification method, turbine perfor- 
mance evaluation method and coolant requirement prediction method.

\subsection{Stator-Blade Geometry}

In this research, the second stator of the GE E3 highpressure turbine was modified with different levels of twist and compound lean, while the other blades remained unchanged. Figure 1 shows the modified blade rotate in different direction at hub and tip, while keeping the throat area unchanged. Open the throat at stator hub and close at tip is called positive twist in this paper, and otherwise called negative twist.

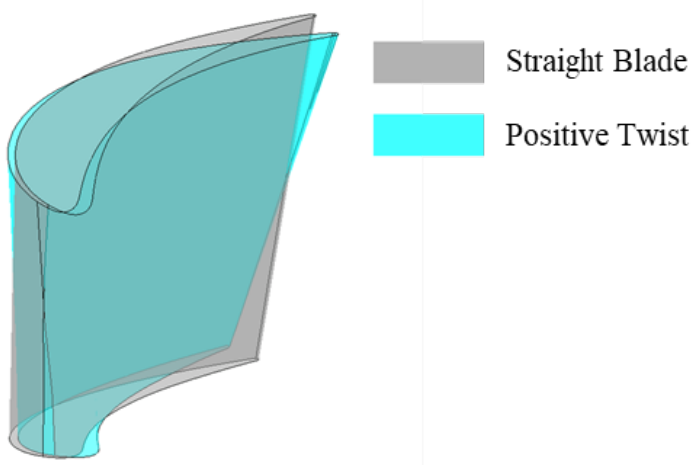

Figure 1: Stator blades with a positive twist

A blade with compound lean indicates that the blade is stacked in a non-radial manner, has its mid-span profile moves in circumferential direction, and the hub and tip are kept still. Figure 2 shows that a positive compound lean indicates that the blade leans to the pressure-surface side, whereas a negative lean is directed to the suction-surface side.
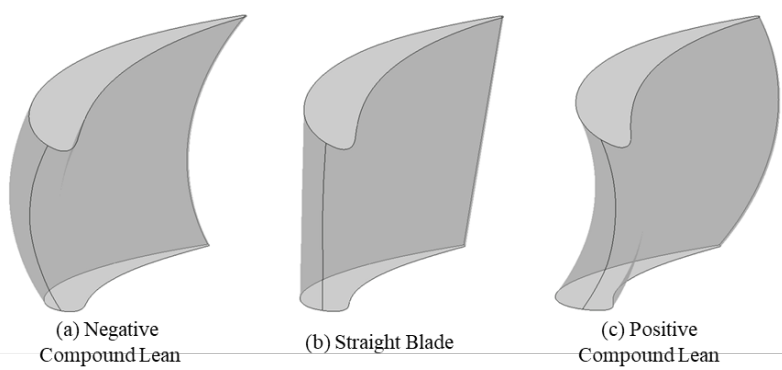

Figure 2: Stator blades with different levels of compound lean
Numerical studies were conducted on turbines with different stator designs, and the influence of both twist and compound lean on the turbine performance was investigated.

\subsection{Turbine-Performance Evaluation}

The numerical simulation method is widely applied to evaluate the turbine performance [20, 21]. The 3D steadystate numerical simulations in this research were performed using ANSYS CFX [19]. The shear stress transport turbulence model with an automatic wall function was selected, and a stage model was adopted at the interface between the rotor and stator. The total pressure and temperature were available at the turbine inlet, whereas the static pressure was available at the turbine outlet.

The computational fluid domain is shown in Figure 3, which considered both the rotor-tip and stator-hub leakages. The leakage path of the first stator was neglected to save computation time, whereas three radial seals were installed in the second stator leakage path to represent a practical structure.

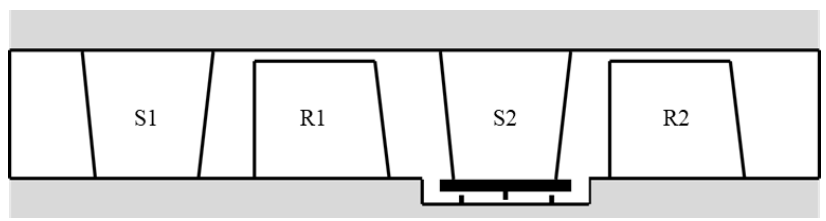

Figure 3: Computational fluid domain that considers the second stator-hub leakage

A 3D structured mesh for each single-flow passage was generated for all the stators and rotors by ANSYSTurboGrid using the H-Grid and O-Grid topologies. The grid number was determined after a grid-independent study, which resulted in the selection of 550,000 and 850,000 cells for the stator and rotor, respectively. The Y plus value for most of the blade surface was approximately one, and the maximum value was less than five.

\subsection{Comprehensive Efficiency}

The application of turbine-cooling technology leads to a significant interaction effect between the turbine mainstream gas and coolant flows, which makes the development of efficiency definition that represents the turbine performance more complicated. In the open literature, unmixed [22] and mixed [23] expansion efficiencies are pre- 
sented to evaluate the cooled-turbine performance. The main difference is in the assumption on the mixing of the mainstream gas with coolant under an ideal process. However, the abovementioned efficiency definitions mainly focus on evaluating the cooled-turbine aerodynamic performance and are insufficient for evaluating the overall effect of a cooled-turbine design on the gas-turbine cycle.

In addition to the turbine aerodynamic efficiency, turbine coolant fraction is one of the important indicators for evaluating how a cooled turbine influences the cycle performance. High-pressure cooling air is always extracted from the compressor, and the coolant fraction significantly influences the cycle performance. Therefore, the cyclebased comprehensive efficiency [15] is developed, which considers both the turbine aerodynamic performance and coolant requirement to evaluate the cooled-turbine comprehensive performance.

The comprehensive efficiency of a cooled turbine can be expressed by the following equation:

$$
\eta_{T, \mathrm{Com}}=\frac{W_{a c}}{W_{i d}}=\frac{\left(1-f_{c}\right)\left(h_{t 3}-h_{t 4}\right)+f_{c}\left(h_{t 1}-h_{t 4}\right)}{\left(1-f_{c}\right) h_{t 3}\left(1-\pi_{T}^{1-\gamma / \gamma}\right)}
$$

where compressor inlet total enthalpy $h_{t 1}$ is included to consider the work added to the coolant to obtain high pressure. More details about the comprehensive efficiency of the cooled turbine can be found in the original paper [15], and the comprehensive efficiency is selected as the optimized objective in this study to evaluate turbines with different stator designs.

\subsection{Coolant-Requirement Prediction}

After evaluating the aerodynamic performance of the redesigned turbine using numerical simulation, the coolantrequirement change compared with that in the baseline design is also required to compare the comprehensive performance of the redesigned turbine. Therefore, a simplified model is developed to predict the coolant requirement of the redesigned turbine.

Figure 4 shows that the allowable blade-metal temperature increases, whereas the bending stress decreases. Therefore, under the force condition of the second stator, which is determined in the CFD simulation, the bending stress of the blade is determined using a finite element method (FEM) simulation [24]. The allowable metaltemperature change can then be determined by comparison with the baseline design.

The blade-cooling efficiency is defined as follows:

$$
\eta_{c}=\frac{T_{g}-T_{m}}{T_{g}-T_{c}}
$$

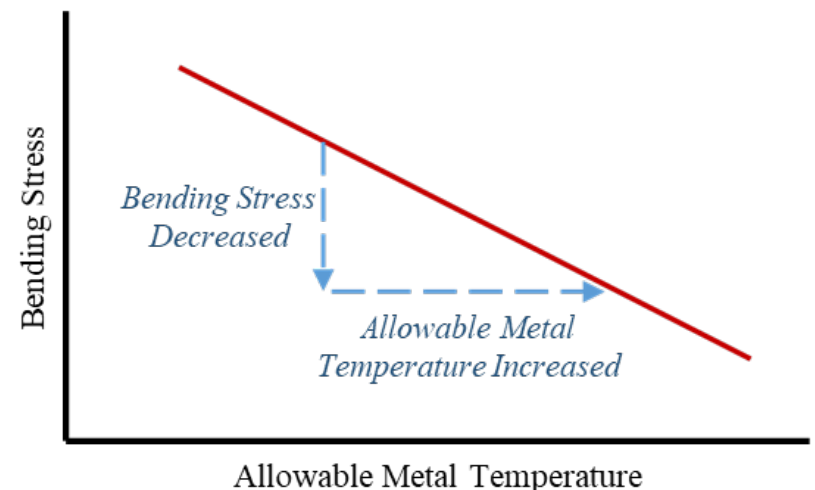

Figure 4: Allowable metal-temperature change with bending stress

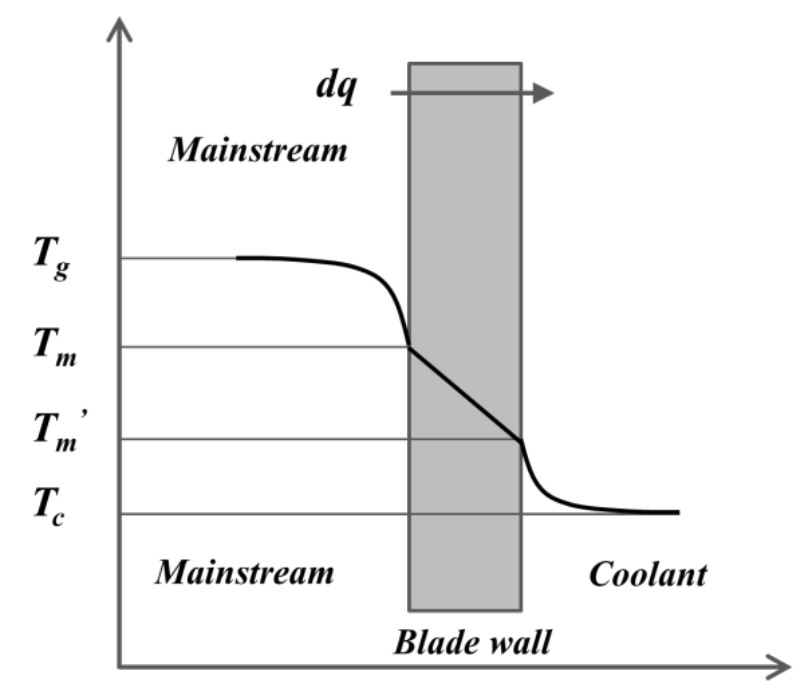

Figure 5: Heat transfer from the mainstream to the coolant [25]

where $T_{g}$ is the mainstream gas temperature, $T_{m}$ is the blade-metal temperature, and $T_{c}$ is the coolant temperature. When the blade-metal temperature changes with the allowable metal temperature, the blade-cooling efficiency also changes, which requires greater or smaller coolant fraction.

The heat transfer from the mainstream to the coolant through the blade surface is shown in Figure 5 where heat convection between the fluid and metal and heat conduction through the blade occur. The blade-cooling efficiency can then be expressed using the heat-transfer process as follows:

$$
\eta_{c}=\frac{T_{g}-T_{m}}{T_{g}-T_{c}}=\frac{\frac{d q}{h_{g}}}{\frac{d q}{h_{g}}+\frac{\lambda}{\Delta l} d q+\frac{d q}{h_{c}}} \approx \frac{1}{1+\frac{h_{g}}{h_{c}}}
$$

For the heat convection between the coolant and blade metal, when the cooling structure is kept unchanged, the relationship between the convection heat-transfer coeffi- 


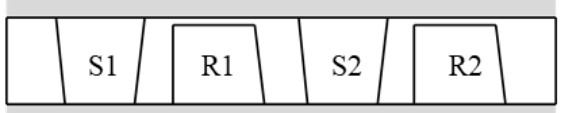

(I) Rotor Leakage

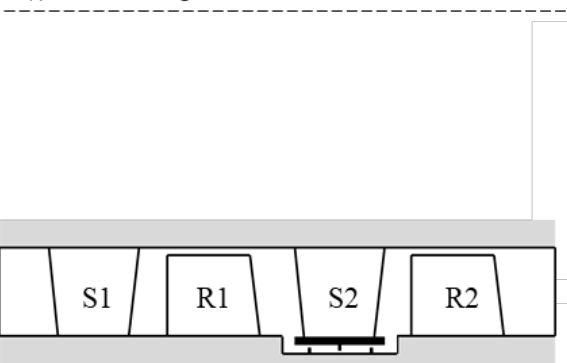

(II) Rotor Leakage \& Second Stator Leakage
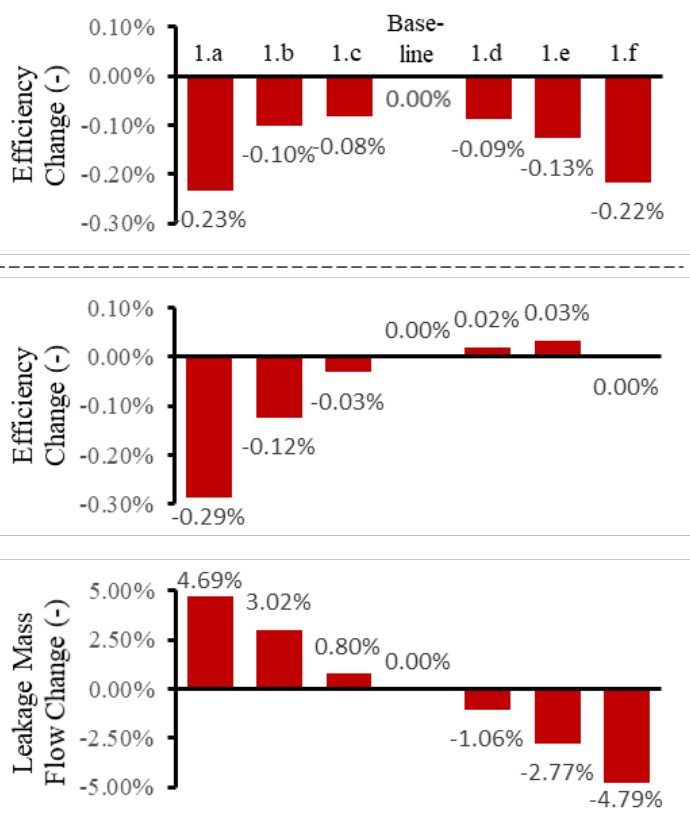

Figure 6: Influence of the stator twist on the turbine performance

Table 1: Stators with blade twist

\begin{tabular}{ccccccc}
\hline Case & $1 . \mathrm{a}$ & 1.b & 1.c & 1.d & 1.e & 1.f \\
\hline Rotating angle at hub $\left(^{\circ}\right)$ & -5 & -3 & -1 & 1 & 3 & 5 \\
$\begin{array}{c}\text { Rotating angle at tip }\left(^{\circ}\right) \\
\text { Type of twist }\end{array}$ & 4.77 & 2.84 & 0.94 & -0.93 & -2.76 & -4.57 \\
& & Negative twist & & \multicolumn{3}{c}{ Positive twist } \\
\hline
\end{tabular}

cient $\left(h_{2}\right)$ and coolant mass flow rate can be expressed as follows:

$$
h_{c} \propto N u_{c} \propto \operatorname{Re}_{c}^{0.8} \propto m_{c}^{0.8}
$$

Therefore, the coolant requirement for the redesigned turbine can be estimated as follows:

$$
\frac{m_{c}^{\prime}}{m_{c}}=\left(\frac{\frac{1}{\eta_{c}}-1}{\frac{1}{\eta_{c}^{\prime}}-1}\right)^{1.25}
$$

From Eq. (2) and Eq. (5), the coolant requirement of the redesigned turbine can be estimated based on the bladebending-stress change, which is used to evaluate the turbine comprehensive efficiency and turbine aerodynamic performance.

\section{Results}

Compared with traditional 3D optimal design, the influence of the coolant-requirement change on the cycle performance is considered in this study, and a numerical simulation is carried out in an environment with a stator-hub leakage. Therefore, the influence of the blade twist and lean on the turbine coolant requirement and stator-hub leakage is principally investigated.

\subsection{Influence of the Blade Twist on the Turbine Performance}

Simulations of turbines with different levels of blade twist were initially conducted, and the redesigned turbines were distinguished according to the rotation angle of the stator hub. In each design, the stator tip was rotated in the opposite direction for a certain angle to keep the mass flow rate constant. The rotating angle in each case is listed in Table 1 in which the opening and closing of the throat were defined as positive and negative twist, respectively.

Numerical simulations of the abovementioned redesign cases were carried out under the conditions where the second stator-hub leakage was both considered and not considered. Figure 6 shows that both positive and negative twists deteriorated the turbine performance when the stator-hub leakage was not considered, as shown in Fig- 


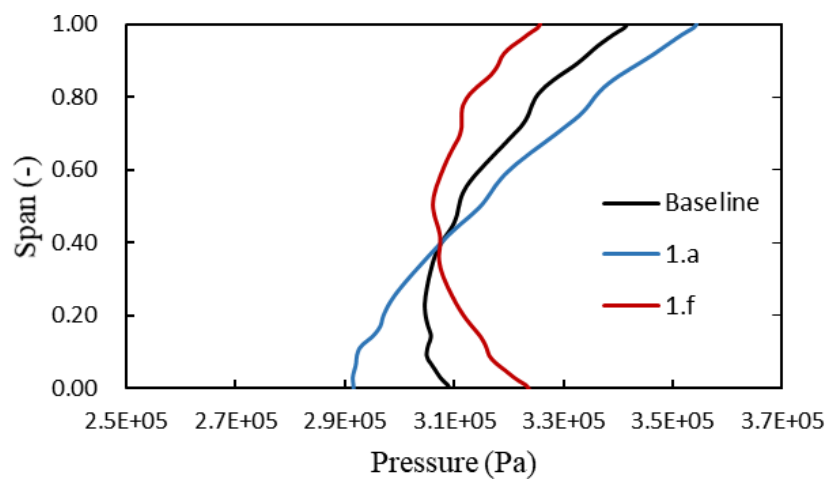

Figure 7: Influence of the stator twist on the pressure distribution

ure 6. The results illustrated that the original design of the GE E3 high-pressure turbine already had a properly twisted stator; further twist modification would result in a negative influence on the stage match and decrease the turbine aerodynamic efficiency. For the numerical simulation that considered stator-hub leakage, the efficiency of the redesigned turbine with a positive-twist stator first increased and then decreased. This indicated that for a positive twist with a small rotation angle, the positive influence of the leakage decrease was dominant, whereas for a positive twist with a large rotation angle, the negative influence of the stage mismatch was dominant.

When the stator-hub leakage was considered in the numerical simulation, the highest efficiency case was found in the design with a positive-twist stator, and the hubleakage flow decreased with increasing positive-twist angle. The reason for these influences is discussed next.

Figure 7 shows the radial-pressure distribution downstream of the second stator with different levels of blade twist. When the throat area in the stator hub was open, the blade loading at the stator hub and the pressure difference across the blade decreased, which led to a smaller leakage mass flow rate and smaller reaction at the stator hub.

In this research, the blade-bending stress was determined using the FEM simulation under the force condition determined by the CFD simulation. The coolantrequirement change was then calculated using the coolantrequirement prediction model. Figure 8 shows that the positive-twist stator could help reduce the blade-bending stress and coolant requirement.

Figure 9 shows that the pitch-wise averaged yaw angle indicated that the positive-twist stator could lead to a smaller flow deflection at the blade hub and a large flow deflection at the blade tip. This result indicated that the blade loading moved from the blade hub to the blade tip, and the bending stress decreased because the stator was fixed on the casing.

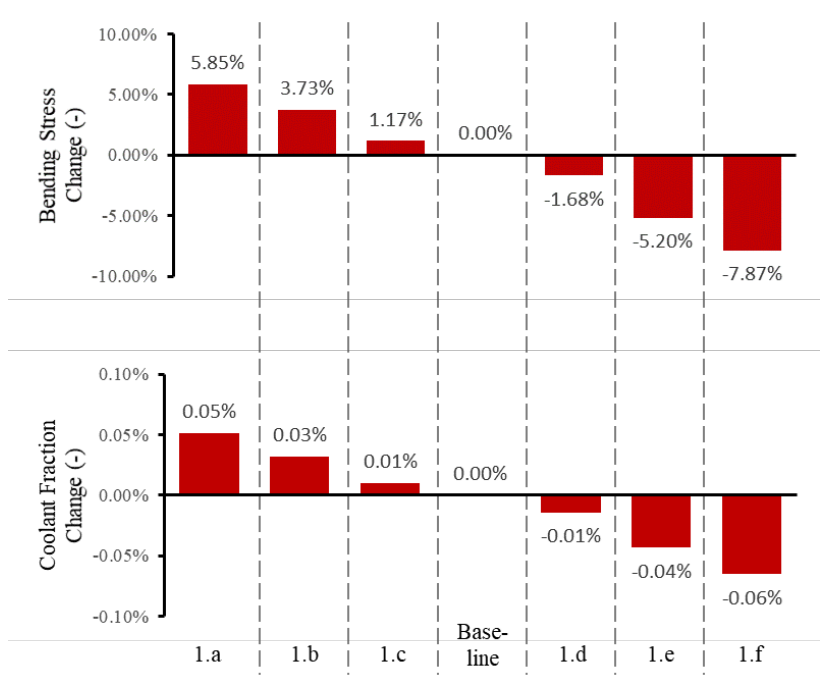

Figure 8: Influence of the stator twist on the bending stress and coolant requirement

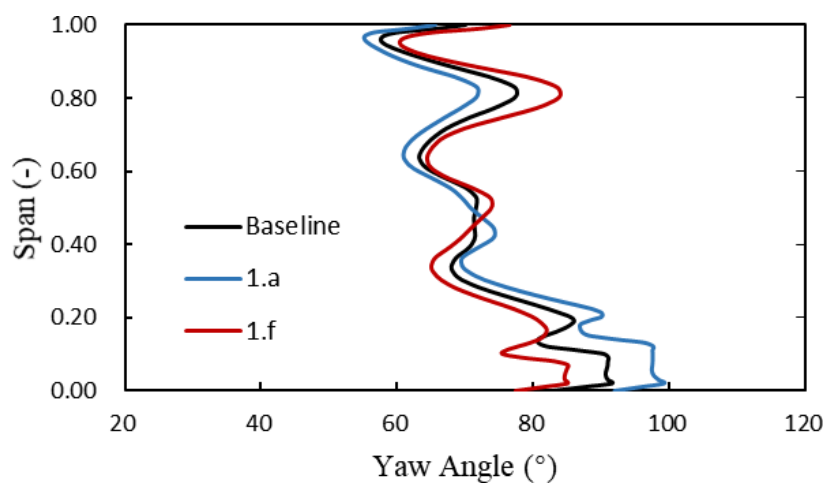

Figure 9: Pitch-wise averaged yaw angle downstream of the second stator

\subsection{Influence of Compound Lean on the Turbine Performance}

The second stator was also modified with both negative and positive compound leans, and the compound-lean stators were distinguished according to the shift distance of the mid-span profile in the circumferential direction. Positive direction was defined as a lean to the pressure surface, and negative direction was defined as a lean to the suction surface. The redesigned turbines with a compound lean, as listed in Table 2, were analyzed in this study.

Figure 10 shows that compared with the baseline design, the cases with a positive compound lean led to a higher aerodynamic efficiency and lower stator-hubleakage mass flow rate, although the change in efficiency was insignificant, which was the same as the results obtained by Rosic and $\mathrm{Xu}$ [11]. 
Table 2: Stators with a compound lean

\begin{tabular}{ccccccc}
\hline Case & $2 . a$ & $2 . b$ & $2 . c$ & $2 . d$ & $2 . e$ & $2 . f$ \\
\hline $\begin{array}{c}\text { Shift distance of mid span }(\mathrm{mm}) \\
\text { Type of lean }\end{array}$ & -10 & -6 & -2 & 2 & 6 & 10 \\
Negative compound lean & & Positive compound lean \\
\hline
\end{tabular}

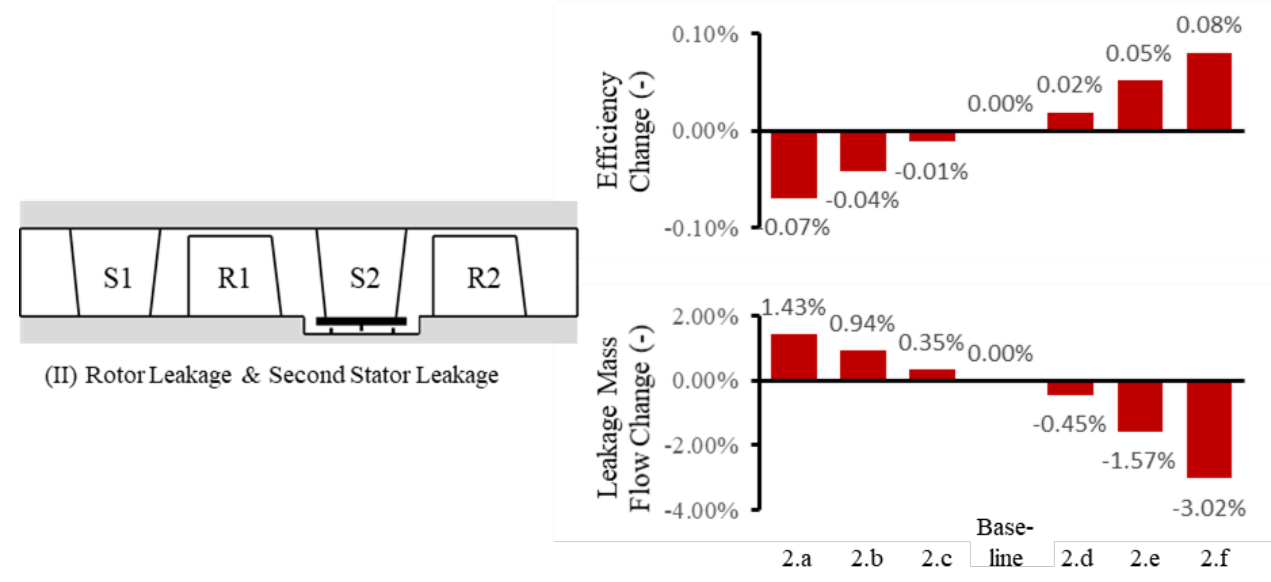

Figure 10: Influence of the compound lean on the turbine performance

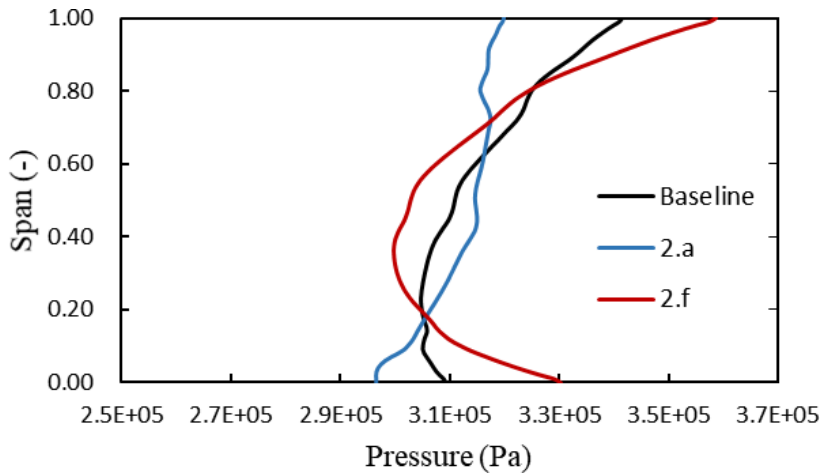

Figure 11: Influence of the compound lean on the pressure distribution

The positive compound lean was proven to reduce the loading at both the hub and casing and increased the loading at mid span [11]. Therefore, the pressure drop across the second stator hub and tip decreased when the stator was modified with a positive compound lean and increased when the stator was modified with a negative compound lean. Figure 11 shows that the positive-compoundlean case exhibited the highest pressure at the hub and casing and the lowest pressure at mid span, which led to a smaller hub-leakage mass flow, as shown in Figure 10.

The blade-bending stress in the compound lean cases were also determined using the FEM simulation, and Figure 12 shows that the bending stress rapidly increased with the negative compound lean, whereas the positive com-

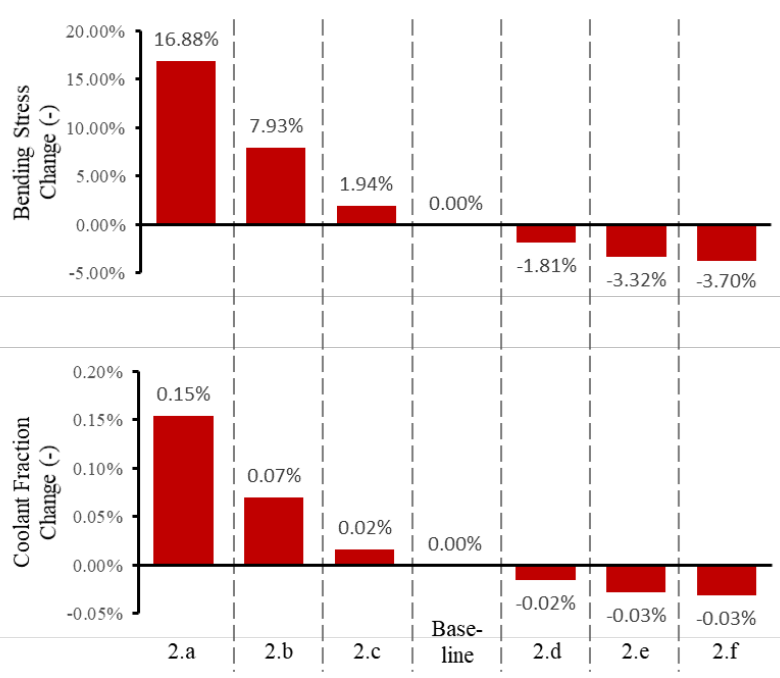

Figure 12: Influence of the compound lean on the bending stress and coolant requirement

pound lean initially decreased the bending stress. However, further reduction of the bending stress was difficult with a larger compound lean. By considering the influence of the compound lean on both the hub leakage and bending stress, the positive compound lean appeared to be a promising method for improving the cooled-turbine comprehensive efficiency. Therefore, the second stator was modified with a blade twist and a positive compound lean, as presented in the next section, and the positive com- 

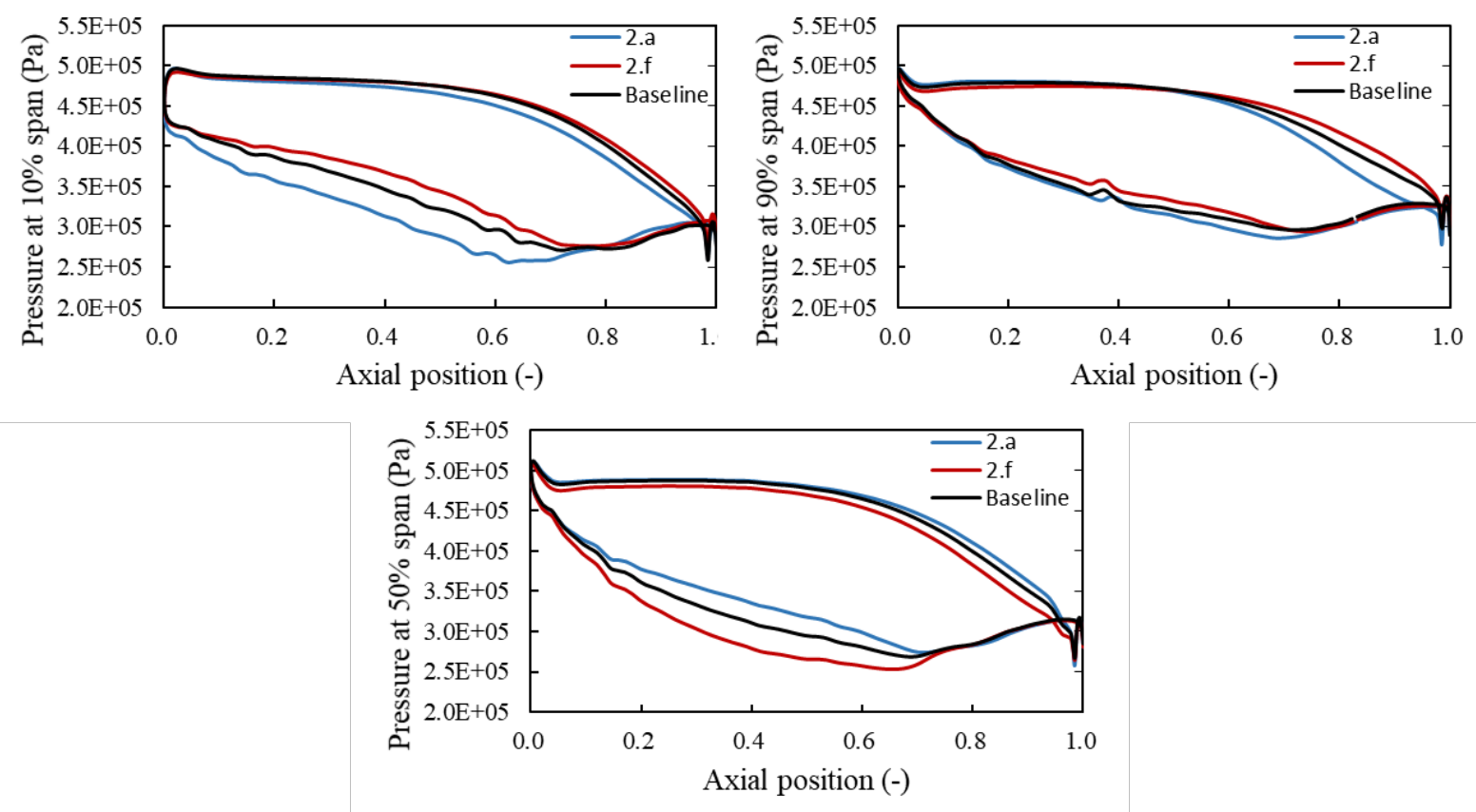

Figure 13: Influence of the compound lean on the blade loading

pound lean was fixed at $10 \mathrm{~mm}$ for the trade-off in the turbine performance and manufacturability.

Figure 13 shows the blade loading of the second stator in different spans. Obviously, a positive compound lean helped reduce the loading at the tip and increased the loading at mid span. Meanwhile, the change in the blade loading at the tip was not very obvious, which means that the radial transport from the stator hub to the mid span was more significant than that from the tip to the mid span. This result helped reduce the maximum bending stress that could occur at the stator tip [26], which was also proven by the FEM simulation.

\subsection{Combined Effect of the Turbine Redesign}

Considering that both positive blade twist and positive compound lean will help reduce the stator-bending stress, the redesigned turbines with twisted and leaned blade were investigated. The combination of cases 1.f and 2.f with a $5^{\circ}$ positive twist and $10-\mathrm{mm}$ positive compound lean was first investigated. The turbine performance comparison between these redesigned turbines are shown in Figure 14, which demonstrates that case 3 further reduced the statorhub leakage and stator bending stress, whereas the aerodynamic efficiency was almost the same as that in the baseline design.

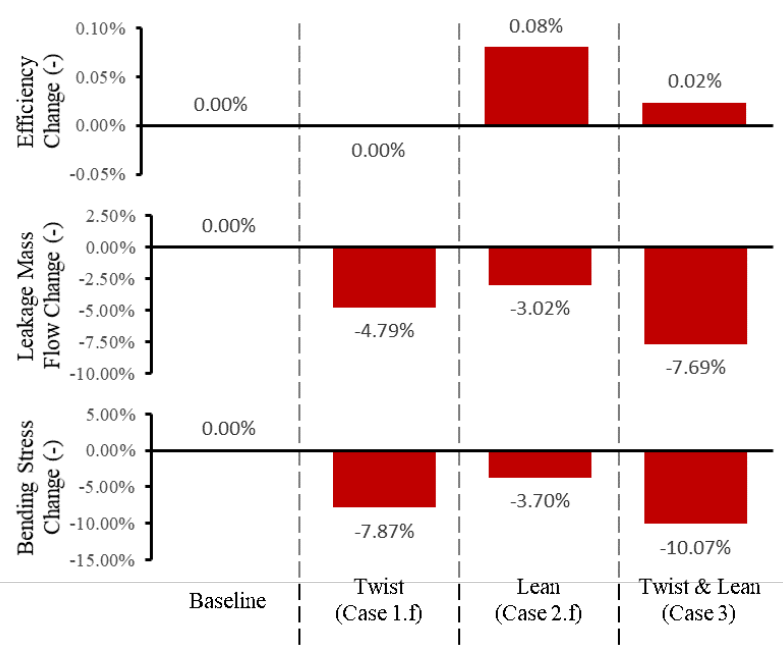

Figure 14: Comparison of the redesigned-turbine performance

The pressure distribution downstream of the second stator in case 3 was influenced by both the blade twist and compound lean, as shown in Figure 15. The pressure at the hub was further improved because of the decrease in the load, and the pressure at the tip was almost the same as that in the baseline design because the positive twist and positive compound lean exerted opposite influence on the pressure at the tip. The stator-outlet Mach number distribution was more non-uniform in case 3 than that in the baseline design, which led to more vortex and loss downstream. Thus, the efficiency of case 3 was almost the same as that 
Table 3: Stators with compound lean

\begin{tabular}{ccccccccc}
\hline Case & $3 . a$ & $3 . b$ & $3 . c$ & $3 . d$ & $3 . e$ & 3 & $3 . f$ & $3 . g$ \\
\hline Rotating angle at hub $\left(^{\circ}\right)$ & 0 & 1 & 2 & 3 & 4 & 5 & 6 & 7 \\
Shift distance of mid span $(\mathrm{mm})$ & 10 & 10 & 10 & 10 & 10 & 10 & 10 & 10 \\
\hline
\end{tabular}

in the baseline design, whereas less leakage occurred in case 3.

To investigate the combined effect of the turbine redesign further, performance of the cases listed in Table 3 was evaluated using numerical calculation where all cases were modified with a $10-\mathrm{mm}$ positive compound lean, and the positive twist varied from $0^{\circ}$ to $7^{\circ}$.

The variation tendency of the efficiency and coolant fraction shown in Figure 16 was the same as that presented in Section 3.1, where the efficiency first increased with a positive-twist blade and then decreased as a result of the combined effect of the flow-field and statorhub-leakage changes. The gas-turbine cycle efficiency was influenced by both turbine aerodynamic efficiency and turbine-coolant requirement. Therefore, further work is still required to determine the best turbine design for the gas-turbine cycle.

The cycle-based comprehensive efficiency of the cooled turbine was calculated to evaluate the influence of both turbine aerodynamic performance and coolantrequirement fraction on the cycle efficiency, as shown in Figure 16. The cycle efficiency is also shown here to illustrate the importance of considering the comprehensive efficiency as a design objective in the turbine redesign.

All the redesigned turbines exerted positive influence on the cycle performance when the influence of the coolant-requirement change was considered, even for turbines with lower aerodynamic efficiency, compared with the baseline design. This result indicated that some better turbine designs could be achieved by sacrificing the turbine aerodynamic performance for a lower coolant requirement.

The turbine with the highest aerodynamic efficiency among the aforementioned cases was case 3.b, whereas case 3.d showed the highest comprehensive efficiency. Case 3.b could be selected as the final design in the traditional optimal design depending on its aerodynamic performance. However, case 3.d exhibited better performance from the point of view of cycle efficiency. Therefore, the cycle-based comprehensive efficiency is a more reliable evaluation criterion for the cooled turbine, which was aimed at improving not only the component efficiency but also the gas-turbine cycle performance.

\section{Conclusions}

A 3D cooled-turbine optimal design that considers the possible coolant-requirement change and stator-hub leakage has been proposed in this paper. A coolant-requirement prediction model was developed to predict the coolantrequirement change due to the $3 \mathrm{D}$ optimal design, and the influence of the turbine-coolant-fraction change on the gas-turbine cycle performance was considered, whereas this influence was always neglected in the traditional 3D optimal design. The comprehensive efficiency of the cooled turbine was selected as the design objective to consider the influence of both turbine aerodynamic efficiency and coolant-requirement changes, and the result showed that considering the coolant-requirement change in the redesign is more reliable to realize high cycle efficiency.

Numerical simulations were performed for turbines with different levels of blade twist and compound lean, shows that both positive twist and positive compound lean on the stator helped reduce the stator hub leakage. The blade-loading redistribution also helped reduce the bladebending stress, which was proven by the FEM simulation, leading to a smaller coolant requirement.

The comparison between the redesigned turbines demonstrated that the turbine with the highest aerodynamic efficiency did not correspond to that with the highest cycle efficiency, when the influence of coolantrequirement change was considered. Meanwhile, comprehensive efficiency could help select the best turbine from the point of view of cycle efficiency, which illustrated the necessity of considering coolant-requirement change in a cooled-turbine 3D design.

Currently, wide application of the turbine inlet temperature is increasing for higher gas-turbine efficiency and cooling technology. Therefore, coolant-requirement fraction becomes one of the important criteria for evaluating the turbine comprehensive performance, in addition to the aerodynamic performance. This study has demonstrated the importance of considering coolantrequirement change in turbine $3 \mathrm{D}$ optimal design, and suggested the use of turbine comprehensive efficiency (instead of aerodynamic efficiency) as the design objective. The positive twist and positive compound lean of the sta- 

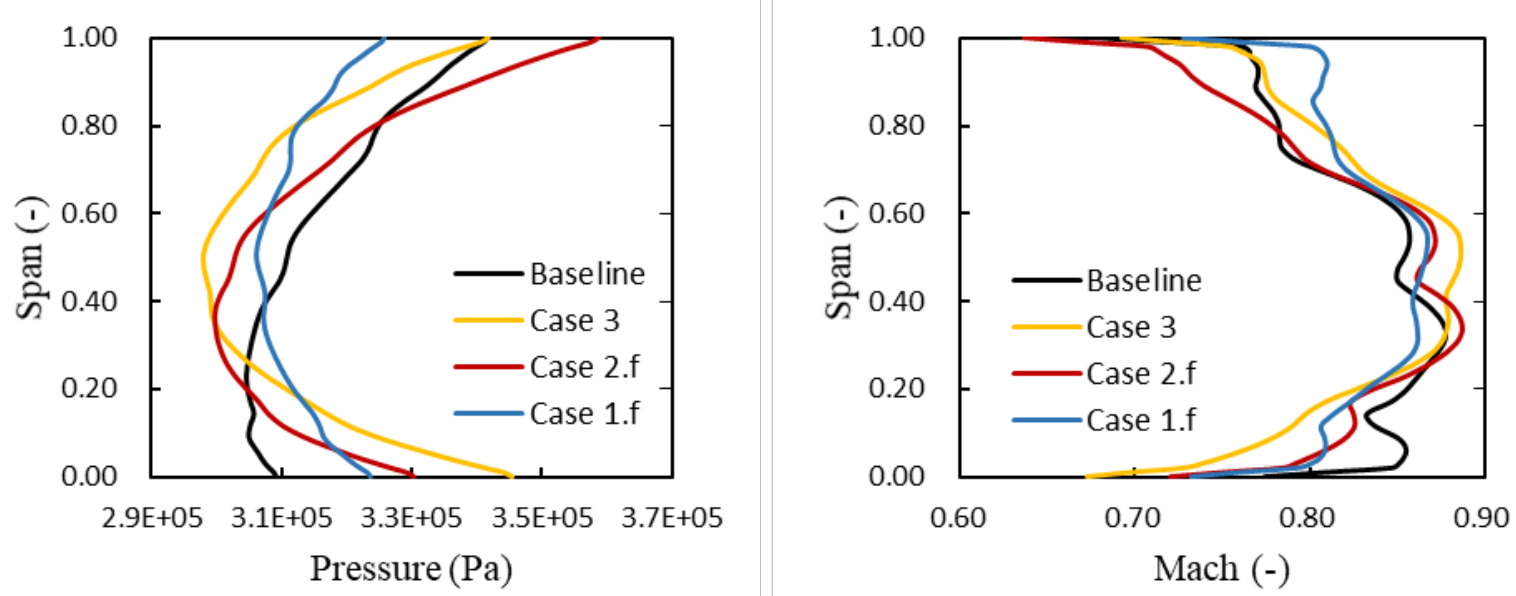

Figure 15: Comparison of the redesigned turbine pressure and Mach number distribution

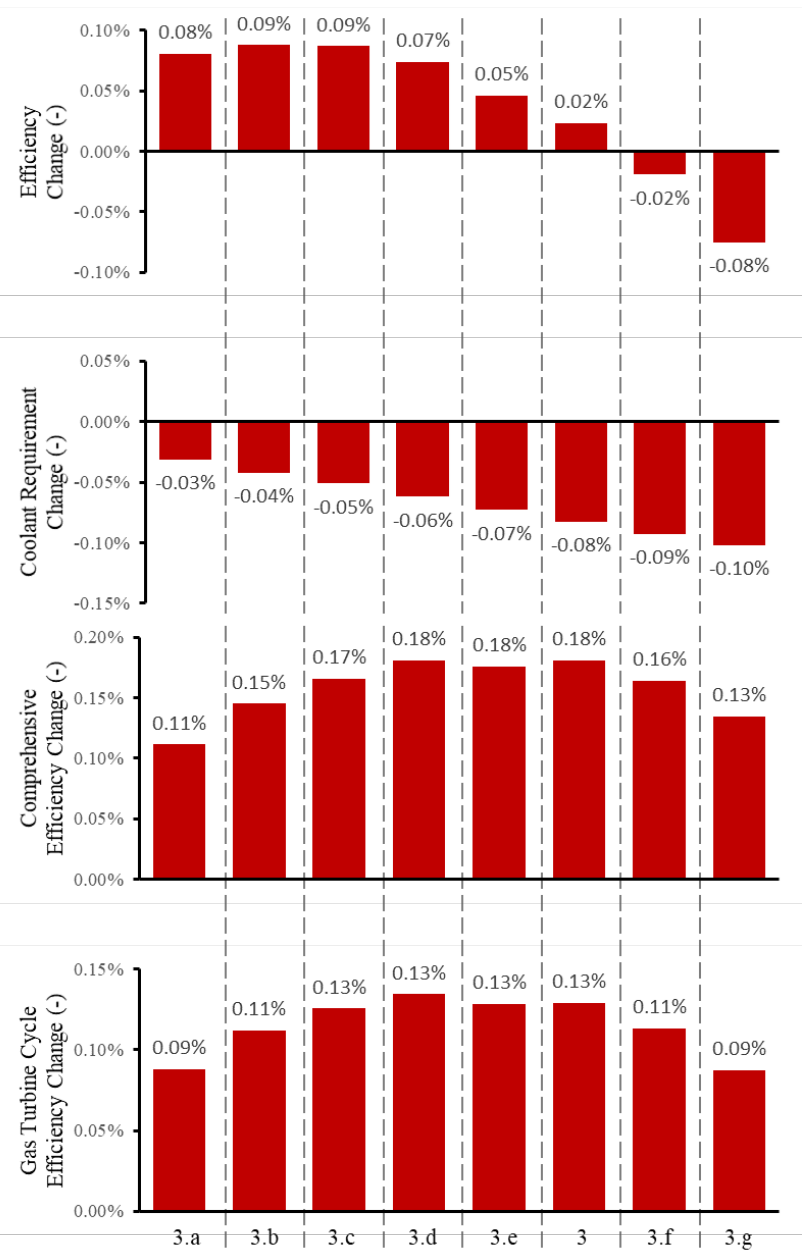

Figure 16: Comparison of the modified turbines

tor was proven to be reliable methods for reducing the coolant requirement, whereas a proper level of twist and lean should be further determined in a practical design by considering the performance, mechanical property, and manufacturing process.

Acknowledgement: This work was supported in part by the National Science and Technology Major Project (No: 2017-III-0009-0035).

\section{References}

[1] Han J. C., Dutta S., Ekkad S., Gas turbine heat transfer and cooling technology, 2012, CRC press, Boca Raton.

[2] Öksüz Ö., Akmandor İ. S., Multi-objective aerodynamic optimization of axial turbine blades using a novel multilevel genetic algorithm, Journal of Turbomachinery, 2010, 132(4): 041009.

[3] Denton J. D., Xu L., The exploitation of three-dimensional flow in turbomachinery design, Proceedings of the Institution of Mechanical Engineers, Part C: Journal of Mechanical Engineering Science, 1998, 213(2): 125-137.

[4] Grant J., Borthwick D., Fully 3D Inviscid Flow Calculations for the Final Stage of a Large, Low-Pressure Steam Turbine, Turbomachinery-Efficiency Prediction and Improvement, 1987: 1987-6.

[5] Hourmouziadis J., Hübner N., 3-d design of turbine airfoils, ASME 1985 International Gas Turbine Conference and Exhibit, American Society of Mechanical Engineers, 1985: V001T03A045V001T03A045.

[6] Staubach J. B., Sharma O. P., Stetson G. M., Reduction of Tip Clearance Losses Through 3-D Airfoil Designs, ASME 1996 Turbo Asia Conference, American Society of Mechanical Engineers, 1996: V001T08A003-V001T08A003.

[7] Singh G., Walker P. J., Haller B. R., Development of 3D stage viscous time marching method for optimisation of short stage heights, Proc. Of European Conf. On Turbomachinery, Erlangen, 1995.

[8] Wallis A. M., Denton J. D., Comparison of design intent and experimental measurements in a low aspect ratio axial flow turbine 
with three-dimensional blading, ASME 1998 International Gas Turbine and Aeroengine Congress and Exhibition. American Society of Mechanical Engineers, 1998: V001T01A123- V001T01A123.

[9] Ren X., Gu C., Application of a discontinuous Galerkin method on the compressible flow in the transonic axial compressor, Applied Thermal Engineering, 2016, 93: 707-717.

[10] Li Y., Ren X., Investigation of the organic Rankine cycle (ORC) system and the radial-inflow turbine design, Applied Thermal Engineering, 2016, 96: 547-554.

[11] Rosic B., Xu L., Blade lean and shroud leakage flows in low aspect ratio turbines, Journal of Turbomachinery, 2012, 134(3): 031003.

[12] Rahim A., Khanal B., He L., et al, Effect of Nozzle Guide Vane Lean Under Influence of Inlet Temperature Traverse, Journal of Turbomachinery, 2014, 136(7): 071002.

[13] Song Y., Gu C., Ji X., Development and validation of a full-range performance analysis model for a three-spool gas turbine with turbine cooling, Energy, 2015, 89: 545-557.

[14] Chi Z., Liu H., Zang S., Multi-objective optimization of the impingement-film cooling structure of a gas turbine endwall using conjugate heat transfer simulations, Journal of Thermal Science and Engineering Applications, 2018, 10(2): 021004.

[15] Ba W., Wang X., Li X., et al, Definition of cycle based comprehensive efficiency of a cooled turbine, Energy, 2019, 168: 601-608.

[16] He R., Wei X., Hassan N., Multi-objective performance optimization of ORC cycle based on improved ant colony algorithm, Open Physics, 2019, 17(1): 48-59.

[17] Xia L., Li X., Song J., et al, Design and Analysis of S-CO 2 Cycle and Radial Turbine for SOFC Vehicle Waste-Heat Recovery, Journal of Thermal Science, 2019, 28(3): 559-570.
[18] Timko L. P., Energy efficient engine high pressure turbine component test performance report, NASA Report No. CR-168289, 1984.

[19] ANSYS CFX-19.1, 2018, User Manual, ANSYS-CFX

[20] Ren X., Xu K., Shyy W., et al, A multi-dimensional high-order discontinuous Galerkin method based on gas kinetic theory for viscous flow computations, Journal of Computational Physics, 2015, 292: 176-193.

[21] Ren X., Xu K., Shyy W., A multi-dimensional high-order DG-ALE method based on gas-kinetic theory with application to oscillating bodies, Journal of Computational Physics, 2016, 316: 700720.

[22] Hartsel J., Prediction of effects of mass-transfer cooling on the blade-row efficiency of turbine airfoils, 10th Aerospace Sciences Meeting. 1972: 11.

[23] Young J. B., Horlock J. H., Defining the efficiency of a cooled turbine, Journal of turbomachinery, 2006, 128(4): 658-667.

[24] ANSYS Mechanical-19.1, 2018, User Manual, ANSYS- Mechanical

[25] Ba W., Gu C., Ren X., et al, Convective cooling model for aerothermal coupled through-flow method, Proceedings of the Institution of Mechanical Engineers, Part A: Journal of Power and Energy, 2017, 231(2): 133-144.

[26] Arbnia M., Aerodynamic Shape Optimization of Axial Turbines in Three Dimensional Flow, PhD Thesis, Concordia University Canada; 2012. 